•编者按・

\title{
探索青藏高原生物多样性分布格局与保育途径
}

\author{
蒋志刚 $1,2^{*}$ \\ 1 (中国科学院动物研究所, 北京 100101) \\ 2 (中国科学院大学, 北京 100049)
}

\section{Exploring the distribution patterns and conservation approaches of biodi- versity on the Qinghai-Tibetan Plateau}

\author{
Zhigang Jiang ${ }^{1,2^{*}}$ \\ 1 Institute of Zoology, Chinese Academy of Sciences, Beijing 100101 \\ 2 University of Chinese Academy of Sciences, Beijing 100049
}

位于北纬 $25^{\circ}-40^{\circ}$ 之间的青藏高原是世界上面 积最大、平均海拔最高、最年轻的高原, 号称“世界 屋脊”和“世界第三极”。青藏高原寒冷、氧分压低、 降水稀少、紫外线辐射强烈, 许多地区不适合人类 居住甚至是生命禁区, 是亚洲人口最稀少的地区, 是世界上名列南极、格陵兰岛之后的第三人口稀少 地区。2014年, 欧盟联合研究中心(Joint Research Centre, JRC) 以到达下一座50万人口城市的时间为 标准, 发现青藏高原为世界上最遥远、最难到达的 地方(Rheinbach, 2016)。

晚更新世青藏高原的隆升影响了北半球中纬度 地区的大气环流, 阻挡了印度洋的暖湿气流, 使中 亚地区干旱化, 也阻挡了北方寒流, 还影响了地球 的气温、大气圈和水圈。青藏高原特殊的环境和地 貌孕育了独特的生物多样性。高原隆升导致了物种 分化, 然而, 目前发现的高原物种分化仍处于属级 水平。中国学者发现青藏高原推迟了有花植物的分 化(Lu et al, 2018), 还发现新近纪青藏高原哺乳动 物适应辐射与第四纪的冰期动物群以及青藏高原 和北极的现代耐寒动物演化的关系(Wang et al, 2015)。最新研究显示, 青藏高原隆升的时间比过去 认为的要晚, 3,000万年前上升至海拔2,500-3,000 m, 在大约400万年前才达到现有高度(Qiu, 2015)。如果 是这样, 那么青藏高原与有花植物、奇蹄目、偶蹄 目、食肉目动物的进化, 甚至现代人类的起源都有
着更密切的关系。

青藏高原是世界独一无二的, 既是中国的, 也 是亚洲和世界的。青藏高原面积达 257 万 $\mathrm{km}^{2}$, 关系 到中国的生态安全, 也是中亚地区的一道生态安全 屏障。长江、黄河、澜沧江(下游为涺公河)、怒江(下 游为萨尔温江)、雅鲁藏布江(下游为布拉马普特拉 河)、恒河和印度河均起源于青藏高原; 青藏高原的 冰川蕴含着地球上最多的淡水资源。青藏高原通过 影响季风、水资源和生态系统服务而直接影响毗邻 地区的 20 多亿人口, 关系到周边毗邻地区的生态安 全(Qiu, 2015)。

青藏高原正在经历剧烈的气候变化(Zhong et al, 2011)。在青藏高原亚洲季风带, 随着季风变弱、降 水减少, 冰川退缩严重, 湖泊面积缩小, 生态系统 功能降低; 而在青藏高原亚洲西风带, 西风变强带 来了更多冬季降水, 使冰川维持原状甚至扩大, 湖 泊面积扩大, 生态系统功能也在好转。可见, 高原 生物对全球变暖表现出不同的响应。

探索青藏高原、研究青藏高原, 中国研究者责 无旁贷。中国科学院建院以来, 以组织承担大考察、 大科学和大工程为己任, 20 世纪下半叶, 组织了多 次青藏高原综合科学考察, 逐步撩开了青藏高原的 神秘面纱, 认识了青藏高原的生物多样性。近年来, 中国科学院、有关高等院校以及国内外自然保护组 织在青藏高原开展了一系列自然科学考察与自然

\footnotetext{
* 通讯作者 Author for correspondence. E-mail: jiangzg@ioz.ac.cn
} 
保育活动, 特别是生物多样性调查与研究工作。国 家相继建立了三江源、芫塘、可可西里等自然保护 区，还实施了GEF青海三江源生物多样性保护项目。

2016年7月 12-15日，青海省林业厅与联合国开 发计划署驻华代表处在青海省玉树市举行了首届 青藏高原生物多样性保护研讨会, 探讨青藏高原生 物多样性的价值与保护意义。中国科学院、高等院 校、国际组织以及民间团体代表介绍了各自在青藏 高原开展的生物多样性调查监测和研究成果, 以及 在生物多样性保护主流化、保护区管理与能力建设 和社区共管等方面的探索与实践。会议学术委员会 主任陈宜瑜院士介绍了 20 世纪下半叶的青藏高原 综合科学考察, 分析了目前高原生物多样性研究的 发现和不足。

为进一步推动青藏高原生物多样性研究与保护, 我们倡议出版本期“青藏高原生物多样性分布格局 与保育专辑”, 得到了与会和不能到会研究人员的 积极响应。本专辑有如下主要发现:

(1)青藏高原特有物种的分布。崔绍朋等(2018) 模拟分析了白唇鹿(Przewalskium albirostris)的潜在 分布区域, 发现其潜在分布区中心位于高原东部藏 青川三省交界处, 地形、气温季节变化和年降水量 是决定白唇鹿分布的主要因素, 而人类影响的贡献 相对较小, 目前白唇鹿种群现状尚不清楚。野牦牛 (Bos mutus) 是青藏高原特有的大型有蹄类动物, 胡 一鸣等(2018)在西藏㒸塘、青海可可西里调查了野 牦牛种群数量, 结合文献资料分析, 发现目前我国 野牦牛数量在 27,220 到 47,138 头之间, 分布区约 $921,000 \mathrm{~km}^{2}$, 野牦牛种群数量逐年稳步增长。普氏 原羚(Procapra przewalskii) 是青藏高原特有物种, 平晓鸽等(2018)报道了普氏原羚的最新种群数量与 栖息地状况, 分析表明仅有 4 个分布点位于青海湖 国家级自然保护区内，建议在布哈河上游建立普氏 原羚自然保护区，同时建立适当的生态补偿机制, 协调保护与社区发展, 并选取合适地点进行人工繁 育个体迁地放归。

(2)青藏高原生物的特有性与格局。了解这里的 特有物种特征及多样性格局对探讨区系演化历史 和物种保护有重要启示。于海彬等(2018)发现青藏 高原有 3,764 种特有种子植物, 隶属 113 科 519 属, $76.3 \%$ 为草本植物。高原特有植物多样性呈现从高
原东南部向西北部逐渐递减的趋势。胡一鸣等(2018) 分析了喜马拉雅山南坡哺乳动物的垂直分布格局, 发现海拔900-1,400 $\mathrm{m}$ 之间哺乳动物物种多样性最 高，与该地区植被的垂直带分布相吻合; 喜马拉雅 山南坡沟谷是生物扩散通道, 水热条件好、气候稳 定, 为生物创造了栖息条件, 是生物多样性热点地 区，应加强保护。蒋志刚等(2018)探索了青藏高原有 蹄类分布格局与保护现状, 确定了青藏高原动物区 的地理边界, 发现青藏高原有蹄类总种数占中国有 蹄类的 $42 \%$, 其中特有种比例高达 $32 \%, 71 \%$ 为受威 胁物种。发现大额牛(Bos frontalis) 已经在野外灭绝, 仅在高黎贡山山区有人工饲养的群体; 高原有蹄类 物种红色名录指数呈现持续下降趋势, 全球气候变 化将加剧这一趋势; 一些重要有蹄类动物种群与栖 息地没有被自然保护地所覆盖, 在开发青藏高原时, 应实现可持续利用与生物多样性保护的双赢目标。

(3)高原生物多样性和生态系统功能之间的关 系。这是目前陆地生态系统生态学研究的热点。张 中华等(2018)评述了草地类型、退化程度、放牧、 模拟气候变化、刚割、施肥、封育和补播对高寒草 地物种多样性与生态系统功能的影响; 指出今后应 基于物种功能多样性探讨养分资源、外界干扰、环 境波动对生物多样性与生态系统功能之间关系的 影响; 提出了加强放牧管理, 治理退化草地, 维持 生物多样性功能的观点。

(4)自然保护地建设与管理。乔慧捷等(2018)研 究了高原林蛙 (Rana kukunoris)、倭蛙(Nanorana pleskei)、西藏齿突蟾(Scutiger boulengeri)和青海沙 蚚(Phrynocephalus vlangalii)分布点的典型环境变 量, 比较了三江源国家公园体制试点区与三江源自 然保护区环境的异同, 发现国家公园试点区缺少分 布在自然保护区内的两栖爬行类所偏好的环境条 件，从而探讨了受环境制约且扩散能力弱的物种保 护在国家公园建设中可能面临的挑战。武晓宇等 (2018)模拟了三江源区濒危保护植物在未来气候变 化情景下的分布, 发现它们主要分布于该区东部和 南部, 在增温增湿的气候变化情景下, 濒危保护植 物的热点区将向西北部扩大，有利于植物多样性的 维持和提高; 然而, 有些热点区域未被重点保护区 覆盖, 应予以关注和保护。

2003年，三江源国家级自然保护区建立，2005 
年，国家投资75亿元实施《青海三江源自然保护区 生态保护和建设总体规划》。宋瑞玲等(2018)研究了 三江源保护区内生物量的变化, 发现在生态保护工 程实施的2005-2012年间, 草地生物量并没有显著 增加。在全国第一个国家公园一三三江源国家公园 试点中, 三江源国家公园尝试将社区发展与自然保 护结合起来, 通过草原保护奖励补偿、设立护林员 岗位等方式, 鼓励农牧民参与保护实践。赵翔等 (2018)针对三江源国家公园生态管护公益岗位设置, 分析思考了这种以社区为主体的保护形式的经验 教训。

尽管本专辑的文章涵盖了特有种调查、生物多 样性格局分析和保护实践, 然而尚存在过度依赖最 大熵(MaxEnt)模型和野外调查数据量少的不足。

青藏高原是一座研究生物对青藏高原生境、全 球变化适应的自然实验室。青藏高原的生物多样性 研究已经从标本采集、分类、个体生态学研究过渡 到控制实验和遥感监测, 气候等环境要素的监测已 经进入自动监测时代。在三江源国家公园的建设过 程中，国家将继续增大投入。2013-2020年实施《青 海三江源国家生态保护综合试验区总体方案》, 综 合试验区范围将扩展为玉树、果洛、海南、黄南4 个州总面积 39.5 万 $\mathrm{km}^{2}$ 的区域，总投资 160.6 亿元 (www.sdpc.gov.cn)。2018年, 国家发展与改革委员 会颁布了《三江源国家公园总体规划》, 提出了生 态监测与评估预警体系(www.sdpc.gov.cn)。

青藏高原生物多样性研究是大科学研究, 需要 建设大数据体系, 开展跨学科协作, 加强遥感、遥 测, 实现环境要素的自动化监测和记录。青藏高原 生物多样性保育应采取生态系统保护途径, 客观评 估保护效果, 实现生物多样性整体保育目标。

\section{参考文献}

Cui SP, Luo X, Li CW, Hu HJ, Jiang ZG (2018) Predicting the potential distribution of white-lipped deer using the MaxEnt model. Biodiversity Science, 26, 171-176. (in Chinese with English abstract) [崔绍朋, 罗晓, 李春旺, 胡慧建, 蒋志刚 (2018) 基于 MaxEnt 模型预测白唇鹿的潜在分布区. 生物 多样性, 26, 171-176.]

Hu YM, Li WQ, Jiang ZG, Liu WL, Liang JC, Lin YZ, Huang ZW, Qin HH, Jin K, Hu HJ (2018) A wild yak survey in the Chang Tang of Tibet Autonomous Region and Hoh Xil of Qinghai Province, China. Biodiversity Science, 26, 185-190. (in Chinese with English abstract) [胡一鸣, 李玮琪, 蒋志
刚, 刘务林, 梁健超, 林宜舟, 黄志文, 覃海华, 金芘, 胡 慧建 (2018) 西藏㒸塘和青海可可西里无人区野牦牛种 群数量和分布现状. 生物多样性, 26, 185-190.]

Hu YM, Liang JC, Jin K, Ding ZF, Zhou ZX, Hu HJ, Jiang ZG (2018) The elevational patterns of mammalian richness in the Himalayas. Biodiversity Science, 26, 191-201. (in Chinese with English abstract) [胡一鸣, 梁健超, 金崑, 丁志锋, 周 智金金, 胡慧建, 蒋志刚 (2018) 喜马拉雅山哺乳动物物种 多样性垂直分布格局. 生物多样性, 26, 191-201.]

Jiang ZG, Li LL, Hu YM, Hu HJ, Li CW, Ping XG, Luo ZH (2018) Diversity and endemism of ungulates on the Qinghai-Tibetan Plateau: Evolution and conservation. Biodiversity Science, 26, 158-170. (in Chinese with English abstract) [蒋志刚, 李立立, 胡一鸣, 胡慧建, 李春旺, 平晓鸽, 罗 振华 (2018) 青藏高原有蹄类动物多样性和特有性: 演化 与保护. 生物多样性, 26, 158-170.]

Lu LM, Mao LF, Yang T, Ye JF, Liu B, Li HL, Sun M, Miller JT, Mathews S, Hu HH, Niu YT, Peng DX, Chen YH, Smith SA, Chen M, Xiang KL, Le CT, Dang VC, Lu AM, Soltis PS, Soltis DE, Li JH, Chen ZD (2018) Evolutionary history of the angiosperm flora of China. Nature, 554, 234-238.

Ping XG, Li CW, Li CL, Tang SH, Fang HX, Cui SP, Chen J, Wang EG, He YB, Cai P, Zhang Y, Wu YL, Jiang ZG (2018) The distribution, population and conservation status of Przewalski's gazelle, Procapra przewalskii. Biodiversity Science, 26, 177-184. (in Chinese with English abstract) [平 晓鸽, 李春旺, 李春林, 汤宋华, 方红霞, 崔绍朋, 陈静, 王恩光, 何玉邦, 蔡平, 张毓, 吴永林, 蒋志刚 (2018) 普 氏原羚分布、种群和保护现状. 生物多样性, 26, 177-184.] Qiao HJ, Wang XY, Wang W, Luo ZH, Tang K, Huang Y, Yang SN, Cao WW, Zhao XQ, Jiang JP, Hu JH (2018) From nature reserve to national park system pilot: Changes of environmental coverage in the Three-River-Source National Park and implications for amphibian and reptile conservation. Biodiversity Science, 26, 202-209. (in Chinese with English abstract) [乔慧捷, 汪晓意, 王伟, 罗振华, 唐科, 黄燕, 杨 胜男, 曹伟伟, 赵新全, 江建平, 胡军华 (2018) 从自然 保护区到国家公园体制试点: 三江源国家公园环境覆盖 的变化及其对两栖爬行类保护的启示. 生物多样性, 26 , 202-209.]

Qiu J (2015) A sky-high view of the Third Pole: An interview with Tandong Yao and Weiming Fan. National Science Review, 2, 489-492.

Rheinbach R (2016) The World's Most Inaccessible Places: Spotlight on the Tibetan Plateau. http://www.thetravellerspost.com/asia/the-worlds-most-inac cessible-places-spotlight-on-the-tibetan-plateau/. (accessed on 2018-02-05)

Song RL, Wang H, Zhang D, Lü Z, Zhu ZY, Zhang L, Liu YL, Caiwengongbao, $\mathrm{Wu} \mathrm{L}$ (2018) Conservation outcomes assessment of Sanjiangyuan alpine grassland with MODIS-EVI approach. Biodiversity Science, 26, 149-157. (in Chinese with English abstract) [宋瑞玲, 王昊, 张迪, 吕 
植, 朱子云, 张璐, 刘炎林, 才文公保, 吴岗 (2018) 基于 MODIS-EVI 评估三江源高寒草地的保护成效. 生物多样 性, 26, 149-157. ]

Wang XM, Wang Y, Li Q, Tseng ZJ, Takeuchi GT, Deng T, Xie GP, Chang MM, Wang N (2015) Cenozoic vertebrate evolution and paleoenvironment in Tibetan Plateau: Progress and prospects. Gondwana Research, 27, 1335-1354.

Wu XY, Dong SK, Liu SL, Liu QR, Han YH, Zhang XL, Su XK, Zhao HD, Feng J (2018) Identifying priority areas for grassland endangered plant species in the Sanjiangyuan Nature Reserve based on the MaxEnt model. Biodiversity Science, 26, 138-148. (in Chinese with English abstract) [武晓 宇, 董世鬼, 刘世梁, 刘全儒, 韩雨晖, 张晓蕾, 苏旭坤, 赵海迪, 冯憬 (2018) 基于 MaxEnt 模型的三江源区草地 濒危保护植物热点区识别. 生物多样性, 26, 138-148.]

Yu HB, Zhang YL, Liu LS, Chen Z, Qi W (2018) Floristic characteristics and diversity patterns of seed plants endemic to the Tibetan Plateau. Biodiversity Science, 26, 130-137. (in Chinese with English abstract) [于海涁, 张镱锂, 刘林 山, 陈朝, 祁威 (2018) 青藏高原特有种子植物区系特征 及多样性分布格局. 生物多样性, 26, 130-137.]
Zhang ZH, Zhou HK, Zhao XQ, Yao BQ, Ma Z, Dong QM, Zhang ZH, Wang WY, Yang YW (2018) Relationship between biodiversity and ecosystem functioning in alpine meadows of the Qinghai-Tibet Plateau. Biodiversity Science, 26, 111-129. (in Chinese with English abstract) [张中华, 周 华坤，赵新全，姚步青，马真，董全民，张振华，王文颖， 杨元武 (2018) 青藏高原高寒草地生物多样性与生态系 统功能的关系. 生物多样性, 26, 111-129.]

Zhao X, Zhu ZY, Lü Z, Xiao LY, Mei S, Wang H (2018) An observation to the new initiative of community conservation guard posts in the pilot Three-River-Source National Park. Biodiversity Science, 26, 210-216. (in Chinese with English abstract) [赵翔, 朱子云, 吕植, 肖凌云, 梅索南措, 王吴 (2018) 社区为主体的保护：对三江源国家公园生态管护 公益岗位的思考. 生物多样性, 26, 210-216.]

Zhong L, Su Z, Ma Y, Salama MS, Sobrino JA (2011) Accelerated changes of environmental conditions on the Tibetan Plateau caused by climate change. Journal of Climate, 24, $6540-6550$

(责任编辑: 周玉荣) 